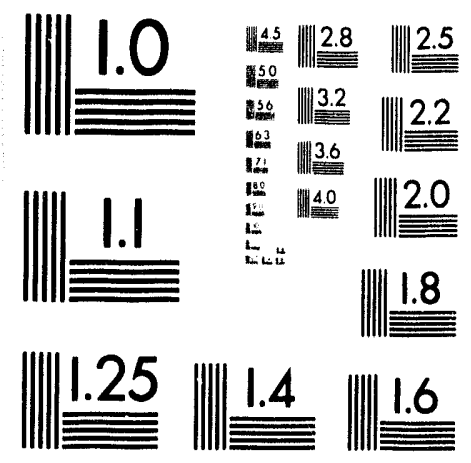



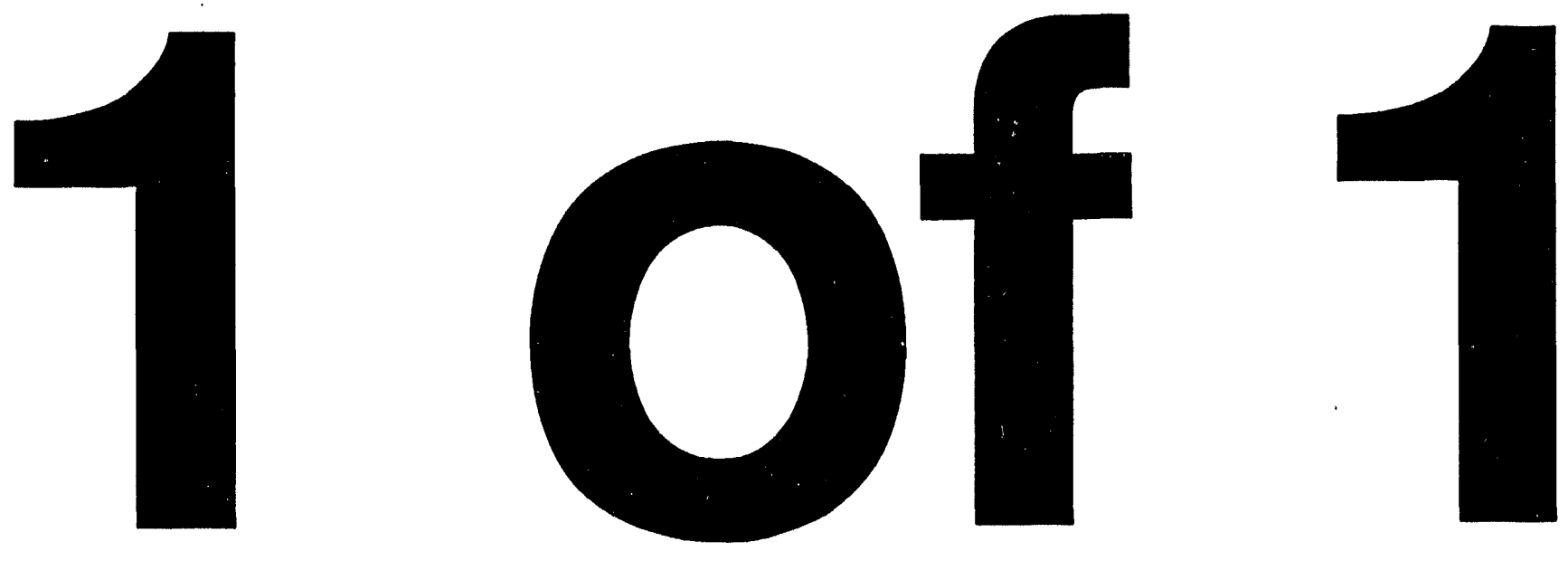


\section{THE ECONOMIC IMPACT OF PROPOSED REGULATIONS ON THE DISCHARGE OF DRILLING MUDS AND CUTTINGS FROM THE OFFSHORE FACILITIES ON U.S. UNDISCOVERED CRUDE OIL RESERVES}

$$
\text { ACOI-88FE } 61679
$$

\section{A. SUMMARY AND OVERVIEW}

This paper presents the results of an assessment of the potential economic impact of proposed regulations on the discharge of drilling fluids (muds) and cuttings on U.S. offshore undiscovered crude oil resources. These regulations include proposed Best Available Tecknology economically achievable (BAT) and New Source Performance Standards (NSPS) effluent limitations under the Clean Water Act governing the discharge of drilling fluids and drill cuttings from offshore oil and gas drilling operations. The Environmental Protection Agency (EPA) proposed these regulations in a Federal Register Notice (53 FR 41356; Oct. 21, 1988) entitled "Oil and Gas Extraction Point Source Category, Offshore Subcategory; Effluent Limitation Guidelines and New Source Performance Standards; New Information and Request for Comments."

This study examines the impact of the proposed NSPS and BAT effluent limitations on the costs of developing undiscovered crude oil resources in the offshore areas of the Lower -48 and Alaska. Since the proposed guidelines address only the discharge of drilling fluids and cuttings, the primary economic impact would be on new projects, and consequently, the development of offshore resources yet-to-be-discovered.

The impacts from several alternative regulatory scenarios were assessed. One scenario assumes that all new projects will be impacted, since operators will often not be able to forecast, a priori, whether the fluids they use or the cuttings they generate will fail prescribed static sheen or toxicity tests. Other scenarios assume that only a specified portion of new projects will be affected, based on forecasts of future drilling operations that will fail the proposed tests.

$06 \mathrm{P00081}$ 
The results of the assessment show that if all projects are assumed to be impacted by the imposition of the proposed regulations, up to $11 \%$ of the U.S. offshore undiscovered crude oil resource would become uneconomic to find, develop, and produce. This amounts to over 800 million barrels at oil prices below $\$ 25$ per barrel (al1 prices in this document are expressed in 1986 dollars). If not all projects are impacted, and operators do not assume that their fluids will be prohibited from being discharged when performing their project evaluations, then only up to $4 \%$ of recoverable reserves will become uneconomic, amounting to 270 million barrels of lost reserves at oil prices below $\$ 25$ per barrel.

Finally, it is important to note that the proposed regulations addressed in this study make up only a portion of the regulatory requirements anticipated to impact the offshore oil and gas industry. The cumulative impact of all these requirements on offshore operations would have a likely impact considerably greater than that estimated in this analysis.

\section{B. PURPOSE}

The purpose of this paper is to present the results of an assessment of the economic impacts of proposed NSPS and BAT guidelines on the discharge of drilling fluids and cuttings from offshore crude oil drilling operations. The analysis is intended to supplement and expand upon economic impact assessments performed by EPA. Since the proposed regulations will impact the cost of offshore well drilling, the greatest impact will be on the development of undiscovered offshore resources in the Lower -48 and Alaska. Thus, this study uses the Replacement Cost of Crude O11 (REPCO) Supply Analysis System, 1,2,3 the Arctic Economics Model (AEM)., ${ }^{4}$ and associated data previously developed for the U.S. Department of Energy/Office of Fossil Energy to examine the costs of developing offshore undiscovered crude oil resources.

\section{DISCLAIMER}

This report was prepared as an account of work sponsored by an agency of the United States Government. Neither the United States Government nor any agency thureof, nor any of their employees, makes any warranty, express or implied, or assumes any legal liability or responsibility for the accuracy, completeness, or usefulness of any information, apparatus, product, or 06P00081 process disclosed, or represents that its use would not infringe privately owned rights. Reference herein to any specific commercial product, process, or service by trade name, trademark, manufacturer, or otherwise does not necessarily constitute or imply its endorsement, recommendation, or favoring by the United States Government or any agency thereof. The views and opinions of authors expressed herein do not necessarily state or reflect those of the United States Government or any agency thereof. 


\section{BACKGROUND}

On August 26, 1985, EPA proposed effluent limitation guidelines and new source performance standards for the oil and gas extraction point source category, offshore subcategory ( 50 FR 34592). The proposal included BAT, NSPS, and Best Conventional Technology (BCT) regulations governing produced water. drilling fluids, drill cuttings, produced sand, deck drainage, well treatment fluids, and sanitary and domestic waste discharges from offshore oil and gas facilities.

Since the August 1985 proposal, EPA received numerous comments and collected additional information on many aspects of the rulemaking. After assimilating and assessing this information, EPA announced new proposed discharge regulations on drilling fluids and drill cuttings. This announcement also summarized the results of EPA's technical, economic, and environmental assessments pertaining to these proposed regulations.

To date, EPA has only announced proposed regulations on the discharge of driling fluids and cuttings. Regulations on the other waste streams included in the original August 1985 proposal will be addressed in separate Federal Register announcements.

The proposed regulations consist of the following limitations:

- No discharge of oil-based fluids or cuttings associated with such fluids

- No discharge of diesel oil in detectable amounts

- No discharge of "free oll" as measured by the static sheen test

- Toxicity limitations measured by a 96-hour LC-50 test

- Limitations on mercury and cadmium concentrations in drilling fluids. 
The effective prohibition on the discharge of oil-based fluids and cuttings associated with such fluids is a continuation of the Best Practical control Technology currently available (BPT) requirement of "no discharge of free oll". Under this requirement, all ofl-based fluids (whether diesel or mineral oil-based) and cuttings associated with such fluids cannot be discharged to surface waters.

The prohibition on the discharge of diesel oil is the result of diesel oil's consideration as an "indicator pollutant" for controlling the discharge of priority pollutants, such as benzene or naphthalene, which are constituents of diesel oil. The prohibition applies to all diesel oil-based fluids, as well as diesel oll used with water-based fluids as a lubricity agent for drilling or "spotting fluid" for freeing stuck pipe. All waste streams containing diesel oil cannot be discharged.

The prohibition of "free oil," as measured by the static sheen test, applies to all waste streams containing ofl-based fluids or associated cuttings that, when discharged, create a visual sheen on the water surface.

The regulations also limit the discharge of fluids that fail a 96-hour LC.50 test, established at a 30,000 parts per million (ppm) concentration (suspended particulate phase basis). This limitation is intended to reduce the concentration of toxic constituents in drilling fluid discharges.

Finally, the regulations place limitations on the concentration of mercury ( $\mathrm{Hg}$ ) and cadmium (Cd) in drilling fluids. These constituents are often found in stock barite, a common additive of drilling fluids. EPA has not yet decided on the exact concentration limits for these two constituents. 


\section{DESCRIPTION OF THE REFERENCE SCENARIO}

The Replacement Cost System has been developed by ICF-Lewin Energy for the DOE/Office of Fossil Energy to provide an analytical framework for resource economic analysis, supply estimation, and policy analysis. The system can be utilized to assess the potential impacts of regulatory proposals, research and development successes, and alternative energy policies on the costs of future domestic crude oil supplies. The models and data which make up this system were used to perform the analyses presented in this paper.

The Replacement Cost System is designed to determine the "replacement cost" of developing domestic undiscovered crude oll reserves. The "replacement cost" is defined as the minimum levelized selling price for a barrel of crude oll that a firm must receive to recover all costs, including royalties and taxes and achleve a reasonable return on capital. This is a "fully riskib" cost based on one theoretical operator developing the reserves while being responsible for drilling all unsuccessful wells. Thus, the replacement cost represents the "full cost" of adding new crude ofl reserves, including:

- Initial investment costs of geological/geophysical work, lease acquisition, unsuccessful wells, and the discovery and delineation wells

- The subsequent investment costs for developing the fleld

- Normal operating costs plus any special costs for conducting waterflooding operations

- Price adjustments to account for oil quality and transportation charges

- Royalties, severance taxes, and appropriate federal and state corporate income taxes

- Return on capital, besed on a discount rate that reflects the long-term return on invested capital within the petroleum industry. 
A reference scenario has been. defined to serve as the basis for comparing al. ternative regulatory scenarios. The reference scenario assumes no incremental costs for drilling fluid management and disposal beyond that currently practiced by offshore operators. The conditions assumed for the reference scenario are consistent with those described in the documentation for Replacement Cost system offshore supply model. ${ }^{3}$ Undiscovered offshore resource estimates used in the system are based on updated estimates provided by the Mineral Mnagement Service (MMS). ${ }^{3}$

Major exploration areas are represented in the Replacement Cost system by the eleven MMS disaggregate regions for the Lower-48 shown in Figure 1 , and the Alaska offshore regions shown in Flgure 2.

The estimates of economically recoverable crude oll resources presented in this study represent the full resource belleved to exist in a particular region. No resources were assumed to be excluded from development due to leasing restrictions or other non-economic factors.

For purposes of this analysis, several modifications were made to the original REPCO and AEM models, as summarized in the paragraphs below.

1. Updated drilling equipment, and eperatine costs. The baseline drilling, equipment, and operating costs assumed in REPCO and AEM were updated to reflect baseline costs in 1986. However, costs are adjusted in the models as a function of the replacement cost, to properly reflect development and production costs at that price. In adjusting costs, a long-term rig utilization rate of $76 \%$ was assumed. This rate represents the utilization rate corresponding to a long-term market equilibrium in the U.S. drilling industry, and is considered appropriate for long-term forecasting. The basis for adjusting costs as a function of crude oil prices and rig utilization rates is described elsewhere. ${ }^{6}$ 
2. Updaced charges for the Trans-Alaska Pipeline System (TAPS). Since 1983, tariffs charged for transporting oil through TAPS have been the subject of extensive litigation. In late 1985, agreement was reached between the U.S. Department of Justice, the State of Alaska, and six of the elght pipeline owners, where tariffs would be determined by an agreed-upon formula, based on the average crude oll flow rate through TAPS. Tariffs under the settlement, on average, will be about $\$ 1$ per barrel less than pre-settlement charges. ${ }^{78}$

\section{Updated financial assumptions resulfine from the Tax Reform Act of}

1986. The 1986 federal tax reform legislation created many changes in the federal income tax law for ofl and gas operations. The new foderal tax code was incorporated into the economic anaiysis of this study.

\section{E. ASSUNPTIONS CONCERNING PROJECTED DRILLING FLUID TOXICITY AND OSE}

Five primary assumptions were made in this analysis to account for future drilling fluid toxiclty and use in offshore drilling operations. First, EPA assumed that all wells drilled to depths less than 10,000 feet would use waterbased drilling fluids. Based on data collected by the American Petroleum Institute (API), $30.8 \%$ of offshore wells are drilled to depths greater than 10,000 feet, and the average depth of these wells is about 14,000 feet. EPA assumed that these deeper wells would use oil-based fluids for the 10,000 to 14,000 foot segment. The drilling fluids and cuttings associated with the drilling of these wells would require onshore disposal (transported by barge) or reuse under BPT regulations; therefore, they would not be impacted by the proposed BAT and NSPS effluent limitations.

However, in the analysis performed here, all wells are assumed to use water-based fluids. Although it is clear that some operators would still use oil-based fluids as a matter of preference or as conditions may dictate, there were no data provided to fustiflably estimate the portions of operations that would still use oil-based fluids. Therefore, for purposes of this impact assessment, only water-based fluids was assumed to be used. 
Second, EPA assumed that a lubricity agent would be required for $12 \%$ of the wells using water-based fluids. It was also assumed that those operators currently using diesel oil lubricity agents would switch to mineral oil agents under the new guidelines. This assumption was used in this analysis.

Third, data collected by the API Offshore Operator's Committee on 2,287 Gulf of Mexico wells showed that $22 \%$ of the wells encountered a stuck pipe incident, requiring the use of a "pill" or spotting fluid to help free the stuck plpe. No distinction was made concerning whether or not a lubricity agent had been used in any of these wells. Thus, this percentage was assumed to apply in all cases in this study.

EPA also assumed that all operators currently using diesel 011 pills would switch to mineral oll pills under the new regulations, because of the discharge restrictions on diesel o11. This was assumed despite the fact that according to the survey, diesel ofl pills were more successful than mineral oll pllis for freeing stuck pipe ( $52.7 \%$ success for diesel oil compared to $32.7 \%$ for mineral 011). The potential impact on operators switching from diesel oil to mineral oll pills was not considered in this analysis.

Fourth, for wells using water-based flulds that require no lubricity agents or spotting fluids, EPA considered a range in the toxicity fallure rate from $2 \%$ to 15\%, based on data supplied to EPA. Assumptions concerning the toxicity and static sheen test fallure rates for water-based drilling fluids and cuttings interact to determine the amount of these fluids that cannot be discharged. This range has quite an effect on compliance costs, since the toxicity limitation appears to be a major cost component of compliance. According to EPA, this accounts for between one-half and three-fourths of total costs.

Finally, where mineral oil has been used for spotting purposes, $22 \%$ of the drilling fluids are assumed to pass both the toxicity and the static sheen test and may be discharged; $56 \%$ are assumed to fall the toxicity test and have to be barged. The remaining $22 \%$ of the drilling fluids to which mineral oil is added 
for spotting purposes are assumed to fall the static sheen test and require barge transport to shore for disposal.

For water-based drilling fluids that have mineral oil added for lubricity purposes, $50 \%$ of the fluids are assumed to pass both the toxicity and the static sheen tests and may be discharged. One third, or $33 \%$, of the fluids are assumed to fall the toxicity test. The remaining $17 \%$ are assumed to fall the static sheen test.

\section{P. EPA REGULATORY SCENARIOS}

For purposes of examining the potential impact of alternative regulatory scenarios on the discharge of driling fluids and cuttings from offshore facilities, EPA proposed four possible regulatory approaches. These approaches were based on different toxiclty fallure rates for water-based drilling fluids to which no oll has been added, and for different sets of effluent limitations for mercury $(\mathrm{Hg})$ and cadmium $(\mathrm{Cd})$ in drilling fluids. These four approaches are summarized below:

Toxicity-Based Fallure Rate for
Water-Based Fluids $(x)^{+}$

A

B

C

D
15

2

15

2
Limitations for $\mathrm{Ho} \& \mathrm{Cd}^{*}$

1,1

1,1

$1.5,2.5$

$1.5,2.5$

tAssumes that no lubricity agents or spotting fluids have been added.

"1, 1 means a minimum acceptable concentration of $1 \mathrm{mg} / \mathrm{kg}$ for mercury and cadmium in discharged drilling fluids; $1.5,2.5$ means a minimum acceptable concentration of $1.5 \mathrm{mg} / \mathrm{kg}$ for mercury and $2.5 \mathrm{mg} / \mathrm{kg}$ for. cadmium in discharged drilling fluids 
In their economic impact assessment, EPA determined the total annual compliance costs for each of the regulatory approaches. These costs accounted for the fraction of wells that would fall toxicity-based effluent limitations and static sheen tests and require disposal. The method of disposal assumed by EPA was transportation to shore by vessel (barge) for reconditioning and reuse (o1l-based fluids) or land disposal (for water-based flulds and cuttings). Incremental costs per well for each approach were decermined by dividing the total annual compliance costs for each approach by 978 wells per year, the estimated annual average, 30-year offshore drilling projections provided by MMS. (Assumed to be constant and independent of the level of increased regulations). These cost estimates for the four regulatory approaches considered by EPA are summarized below:

\section{Approach}

A

B

C

D
Total Estimated Annual Comoliance Costs (Thous and \$)

$$
\begin{aligned}
& 76,617 \\
& 50,662 \\
& 66,113 \\
& 40,158
\end{aligned}
$$

Estimated Incremental Compliance Cost Per Well ( $\$ /$ we11)

$$
78,340
$$

51,802

67,600

41,061

\section{G. ANALYTICAL APPROACH}

The regulatory scenarios examined in this assessment were based on the proposed approaches presented in EPA's Federal Register Notice, with some modifications. For purposes of this study, it is assumed that under the reference scenario, all wells drilled in developing the undiscovered offshore resource base would use water-based fluids. Therefore, all wells would be potentially impacted by the imposition of the proposed regulations. Some drilling operators would still choose oll-based muds for some situations. However, given the data provided by EPA, it is impossible to estimate the fraction of future wells that would require ofl-based fluids. 
Three possible land disposal alternatives were developed by EPA on the basis of the abllity to store the wastes during high seas or offload these wastes for trunsport to shore, and are presented as follows:

- Rigs with no storage space for drilling wastes, but deslgned for loading boats in seas with wave helghts of up to 6 feet. If wave heights exceeded 6 feet, drilling would have to cease for the period that the wave heights were in excess of 6 feet and supply boats were unable to tie up at the facility.

- Rigs with no storage space for drilling wastes, but designed for loading boats in seas with wave helghts of up to 10 feet. If wave heighta exceeded 10 feet, drilling would have to cease for the period that the wave helghts were in excess of 10 feet and supply boats were unable to tie up at the facility.

- Rigs retrofitted for drilling wastes storage. These rigs could continue to drill even when supply boats were unable to tie-up at the facility.

No other treatment or disposal optlons were considered in the ERA economic Impact assessment, and no others were considered in this analysis. The costing assumptions associated with these alternatives were described in detall in the Federal Register Notice.

ERA assumed that the majority of operators would, in all probability, decide to retrofit rigs for drilling fluld storage since this would result in overall lower costs for the disposal of drilling flulds. The costs are lower because supply boats would not be dedicated solely to drilling waste disposal. They estimated that $80 \%$ of the rigs would be retroficted, $10 \%$ would operate using a maximum permissible wave height of 10 feet and $10 \%$ would operate using a maximum permissible wave height of 6 feet. This breakdown was also assumed in these analyses.

Finally, it was assumed in this analysis that if drilling flulds fail the static sheen or toxicity tests and require onshore disposal, then the associaced drill cuttings would also be barged to shore for disposal. EPA assumed separate 
failure rates for fluids and cuttings, with a greater proportion of drill cuttings allowed to be discharged relative to drtiling fluids. Although the allowance for a greater proportion of drill cuttings to be discharged would reduce total compliance costs, the use of this assumption serves to reduce the number of possible discharge scenarios requiring consideration, and consequently simplifies the analysis. It is realized that this assumption could lead to a slight overstatement of economic impacts.

\section{H. DEFINITION OF THE ALTERNATIVE REGULATORY SCENARIOS}

In this analysis, three potential regulatory scenarios were considered. The first scenario, called the Full Impact Scenario, assumes that all waterbased drilling fluids and cuttings associated with such fluids will require onshore disposal. Consideration of this scenario is justifled since most operators will be unable to assume, a priori, whether the drilling fluids they use or cuttings they generate will fail toxicity or static sheen tests, or whether the conditions they encounter will require the addition of potentially toxic additives. These operators, in economically justifying their projects, will assume onshore disposal (as a conservative prospect evaluation).

For the Full Impact Scenario, the estimate of economically recoverable resources was determined using a three step approach. First, an analysis was performed for each of the three disposal alternatives, where, for each case, that alternative was the only disposal option available for all projects. This generated a cost/supply curve for offshore resources for each disposal alternative. Second, the cost/supply curve for the Full Impact Scenario was determined by weighting the cost/supply curves for each of the disposal alternatives by its assumed share of the land disposal market (i.e., $80 \%$ retrofitted rigs, $10 \%$ rigs with no storage designed for 6 foot waves, and 10\% rigs with no storage designed for 10 foot waves) and summing the results. Third, the Full Impact Scenario cost/supply curve was compared to the curve obtained for the reference case to determine the fraction of resource becoming uneconomic as a result of the imposition of the proposed regulations.

$06 \mathrm{P} 00081$ 
The second scenario considered assumes the toxicity test failure rates corresponding to EPA Approaches $A$ and $C$, where $15 \%$ of all wells using waterbased fluids and requiring no lubricity agents or spotting fluids would fail a toxicity test. Based on EPA assumptions concerning the percentages of future wells that require the use of lubricity agents or encounter stuck pipe incidents, and those wells under each situation that would fail either toxicity or static sheen tests, a probability or decision tree was constructed. A decision tree corresponding to Approaches $A$ and $C$ is shown in Figure 3 . Each node on the decision tree represents a potential outcome corresponding to each situation encountered. As shown, $32 \%$ of all offshore wells drilled would require onshore disposal under this approach, since $26 \%$ would fail the toxicity test, and $6 \%$ would fail the static sheen test.

The third scenario considered assumes the toxicity test fallure rates corresponding to EPA Approaches $B$ and $D$, where only 24 of all offshore wells using water-based fluids and requiring no lubricity agents or spotting fluids would fail a toxicity test. A decision tree corresponding to the situations encountered by Approaches $B$ and $D$ is displayed in Figure 4. Approximately $23 x$ of all offshore wells drilled would require onshore disposal under this approach, since $17 \%$ would fail the toxicity test, and $6 \%$ would fail the static sheen test.

The estimate of economically recoverable undiscovered reserves for the second and third scenarios was determined using a three-step process. First, the economic analysis was performed assuming that all projects fail the effluent limitations, based on the average disposal costs for fluids and cuttings assumed by EPA. This case is represented by the cost/supply curve for the Full Impact Scenario. Second, the analysis was repeated under the assumption that all projects pass the effluent limitations and can discharge the fluids and cuttings offshore, thereby incurring no incremental costs. This case is represented by the cost/supply curve for the reference case. 
Third, overall impacts under the specific regulatory approach were determined assuming that the specified percentage of cases that fail the toxicity or static sheet tests and require onshore disposal corresponds to the fully impacted projects, while the cases where offshore discharge is acceptable assume reference conditions. Economically recoverable resources at a given price were determined by selecting the appropriate percentage from the Full Impact and reference cost/supply curves, which were summed to give the economically recoverable reserves under the specific approach. For example, under the scenario corresponding to Approaches $A$ and $C, 23 \%$ of the Full Impact Scenario cost/supply curve was added to $77 \%$ of the reference case cost supply curve to determine the ccst/supply curve corresponding to this scenario.

Finally, as a point of comparison, EPA's regulatory Approach A was also examined using EPA's weighted-average per well compliance cost of approximately $\$ 78,000$ per well. However, it is felt that the use of this weighted-average cost misrepresents the potential impacts corresponding to this scenario. In truth, some projects would feel no impact and would be able to discharge drilling fluids and cuttings with no compllance cost burden, while others would feel the full cost impact (if they fail the toxicity or static sheen test). However, it was felt that it would be instructive to compare the results under this assumption with those obtained for the other sconarlos.

\section{ESTIMATED IMPACTS FOR THE REGULATORY SCENARIOS}

The estimated impacts presented in this paper, as stated previously, are based on the incremental costs of compliance as determined by EPA and its contractors, modified as described previously, and applied to a reference case determined by the models of the Replacement Costs System. The REPCO and AEM models were used to determine the amount of offshore undiscovered crude oil reserves in the U.S. that would become uneconomic at a given price as a result of the proposed regulatory scenarios. The analyses were performed in constant 1986 dollars. In all cases, it was assumed that the imposition of the proposed 
regulations would not affect the timing of development of individual crude ofl projects.

The results presented only pertain to the impacts on offshore resources in the Lower-48 states. The estimated incremental compliance costs for Alaska were small relative to the total costs of finding and developing Alaskan offshore crude ofl resources. Thus, the increased regulations were shown to have a negligible impact under all regulatory scenarios investigated. As a result, the impacts for Alaska are not presented.

Under baseline conditions ( $1 . e .$, reference case), 3.3 billion barrels of Lower-48 undiscovered offshore crude oil resources are estimated to be economi. cally recoverable at an oll price of $\$ 15$ per barrel. Approximately 5.3 billion barrels of economically recoverable reserves are recoverable at $\$ 20$ per barrel, and 7.4 billion barrels of reserves are estimated at an oll price of $\$ 30$ per barrel, as shown below for the Gulf of Mexico, Pacific Coast, Atlantic Coast, and total Lower-48:

\section{Lover -48 offshore Und1scovered crude 012 \\ Reserves for the Reference Scenerto}

\section{Crude 0il Price Economically Recoverable Undiscovered Reserves $(1986 \$ / \mathrm{Bb} 1)$ (Million Barrels)}

\section{Gulf Racific Atlantic Total Lower-48}

$\begin{array}{lllll}15 & 1954 & 1059 & 277 & 3290 \\ 20 & 2725 & 2210 & 339 & 5274 \\ 25 & 3752 & 3117 & 496 & 7365\end{array}$

These estimates serve as the baseline against which all the regulatory scenarios are compared. 
As discussed previously, three possible disposal alcernatives were considered under the Full Impact scenario. These include rigs with no storage space but designed for loading transport vessels in seas with wave heights up to 6 feet, rigs with no storage space but designed for loading transport vessels in seas with wave heights up to 10 feet, and rigs retrofitted for drilling waste storage. The costs of waste transport to shore for watei-based drilling fluids and drill cuttings associated with water-based fluids used for assessing each of three alternatives are the same as those assumed by EPA, and are presented below:

\section{Transport option}

No storage, max. $6 \mathrm{ft}$. waves

No storage, $\max .10 \mathrm{ft}$. waves

Rig retrofitted for storage
Cost of Disposal ( $S / B b 1$ of waste) Drilifine Fluids

Det111 auteings

\section{8}

61

46
58

46

33

For all three alternatives, the costs assumed for onshore landfill disposal were $\$ 6.50$ per barrel of fluid ard $\$ 6.00$ per barrel of cuttings. These costs were added to the transportation costs for each alternative.

Estimates for the amount of fluid and cuttings produced were the same as those assumed by EPA. For a 10,000 foot well, 6,749 barrels of drilling fluids and 1,430 barrels of dr111 cuttings were assumed to be generated.

The impacts on the costs of finding, developing and producing U.S. offshore undiscovered crude oll resources under each of the regulacory scenarios, are presented in Figure 5 and Table 1 . Under the Full Impact Scenario, where all fluids and cuttings would be barged to shore for land disposal, approximately $8 \%$ of the economic resource becomes uneconomic as a result of compliance with the regulations (corresponding to about 276 million barrels) at an oil price of $\$ 15$ per barrel. At $\$ 20$ per barrel, only $2 \%$ of the potentially economic resource is lost (approximately 111 million barrels), while at $\$ 25$ per barrel, $11 \%$ of recoverable reserves become uneconomic (amounting to 
845 million barrels).

Under the two intermediate regulatory alternatives (Approaches $A$ and $C$ and Approaches $B$ and $D$ ), where only a portion of the offshore projects would fail static sheen or toxicity tests ( $32 \%$ and $23 \%$, respectively), up to $4 \%$ of the resource could become uneconomic as a result of the proposad regulations (amounting to 270 million barrels at an oll price of $\$ 25$ per barrel. The greater impact would be felt under Approaches $A$ and $C$, where a greater proportion of the drilling fluids would fail either the toxicity or static sheen test.

Finally, assuming average incremental compliance costs of $\$ 78,000$ per well under EPA Approach $A$, this analys is shows that up to $9 \%$ of the economically recoverable resource would become uneconomic as a result of the proposed regulations. This amounts to nearly 700 million barrels of crude oil at an oil price of $\$ 25$ per barrel.

\section{J. SURDEARY}

The impact of the proposed BAT/NSPS regulations for the drilling fluids and drill cuttings disposal on the cost of funding, developing, and producing Lower-48 offshore undiscovered crude ofl resources will depend significanty on operators perceptions on the chances of falling toxicity or static sheen tests. If operators, In economically fustifying their projects, assume that the fluids fall one of these tests, thereby prohibiting them from being discharged, up to $11 \%$ of the economically recoverable offshore resource would be considered uneconomic to produce. This would amount to 845 million barrels of ofl at an 011 price around $\$ 25$ per barrel.

On the other hand, if operators are willing to take their chances and see if their fluids fail one of these tests, then, based on EPA's assumptions concerning forecast fluid use and static sheen and toxicity test failure rates, up to $4 \%$ of the offshore undiscovered resource would be impacted, amounting to lost reserves of up to 270 million barrels. 
In conclusion, the imposition of the proposed BAT/NSPS could have a considerable impact on U.S. crude oll reserves, where all operations are potentially impacted. In addition, it is important to note that the regulatory requirements considered make up only a portion of the likely regulatory burdens to be imposed on offshore operations, and the cumulative impact of these regulations, when considered together, could have a drastic impact on U.S. crude o1l supplies. 


\section{REPERENCES}

1. Lewin and Associates, Inc., "Replacement Costs of Domestic Crude 011: Final Report." July 1985.

2. Lewin and Associates, Inc., "Replacement Costs of Dowestic Crude O11: Supply Analysis Methodology," July 1985

3. ICF-Lewin Energy, A Model for the Econemic Anslysis of U, S. Undiscovered Crude 0il Resources in the Lower 48 Offshore, report prepared for the U.S. DOE/Office of Fossil Energy, under Contract No. DE-ACO1-85FE60603, June 1988.

4. Lewin and Associates, Inc., "Arctic Economics Model (AEM)," report prepared for the U.S. Department of Energy/Office of Fossil Energy, August 1985.

5. U.S. Department of Interior, U.S. Geological Survey/Minerals Management Service, National Assessment of Undiscovered Conyentionel 012 and cas Resources, USGS-MMS WorkIng Paper Open-F1le Report 88.373, 1988

6. Kuuskraa, V.A., F. Morra. Jr., and M.L. Godec, "Importance of Cost/Price Relationships for Least-Cost 011 and Gas Reserves," SPE Paper 16289, presented at the 1987 SPE Hydrocarbon Economics and Evaluation Symosium, Dallas, Texas, March 1987.

7. U.S. Department of Commerce "Report to Congress on Alaskan 011 - Section 126 of the Export Administration Amendments Act of 1985," June 1986.

8. Personal Communication: C.V. Chatterton, Alaska 011 and Gas Conservation Commission, November 7, 1986. 

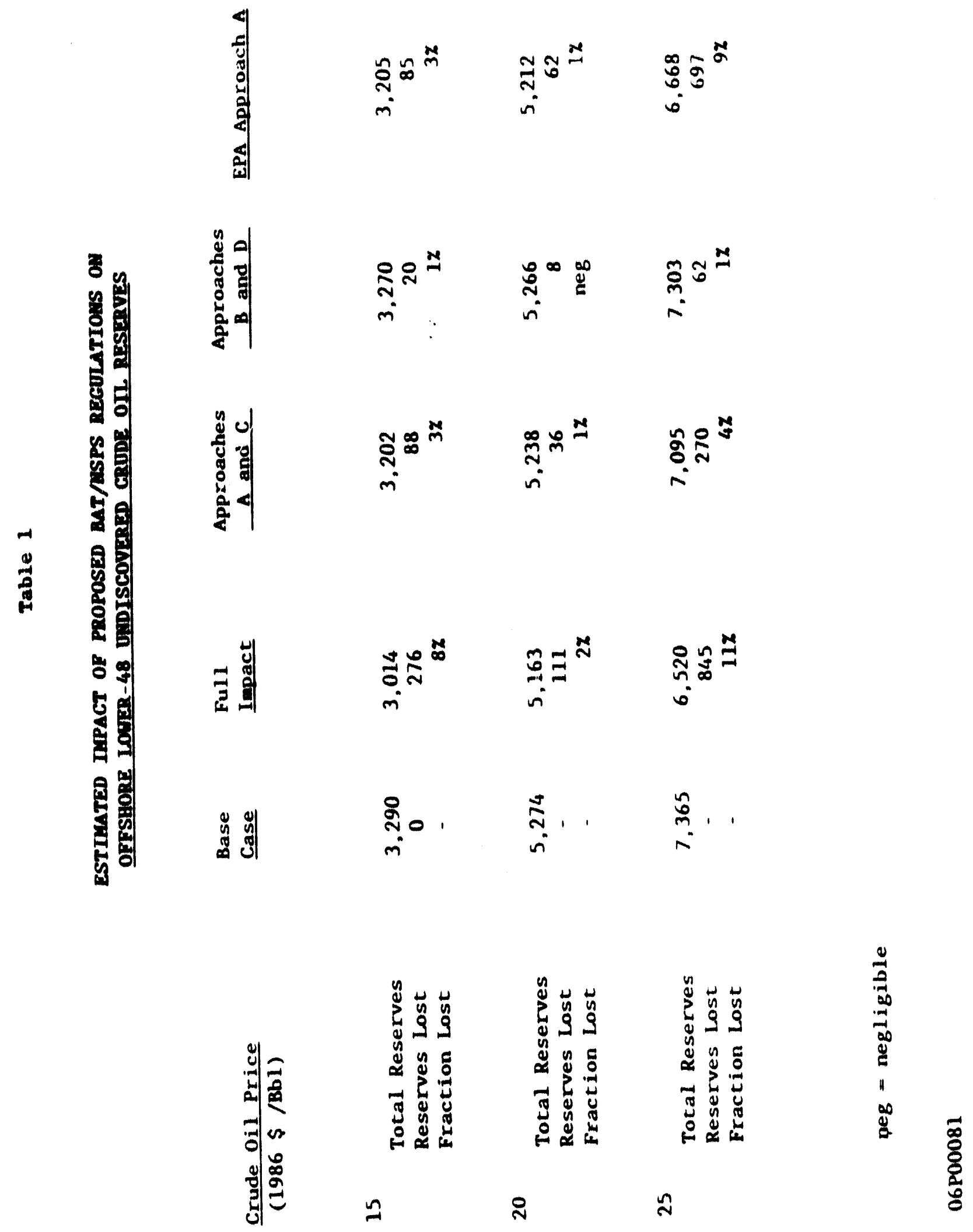


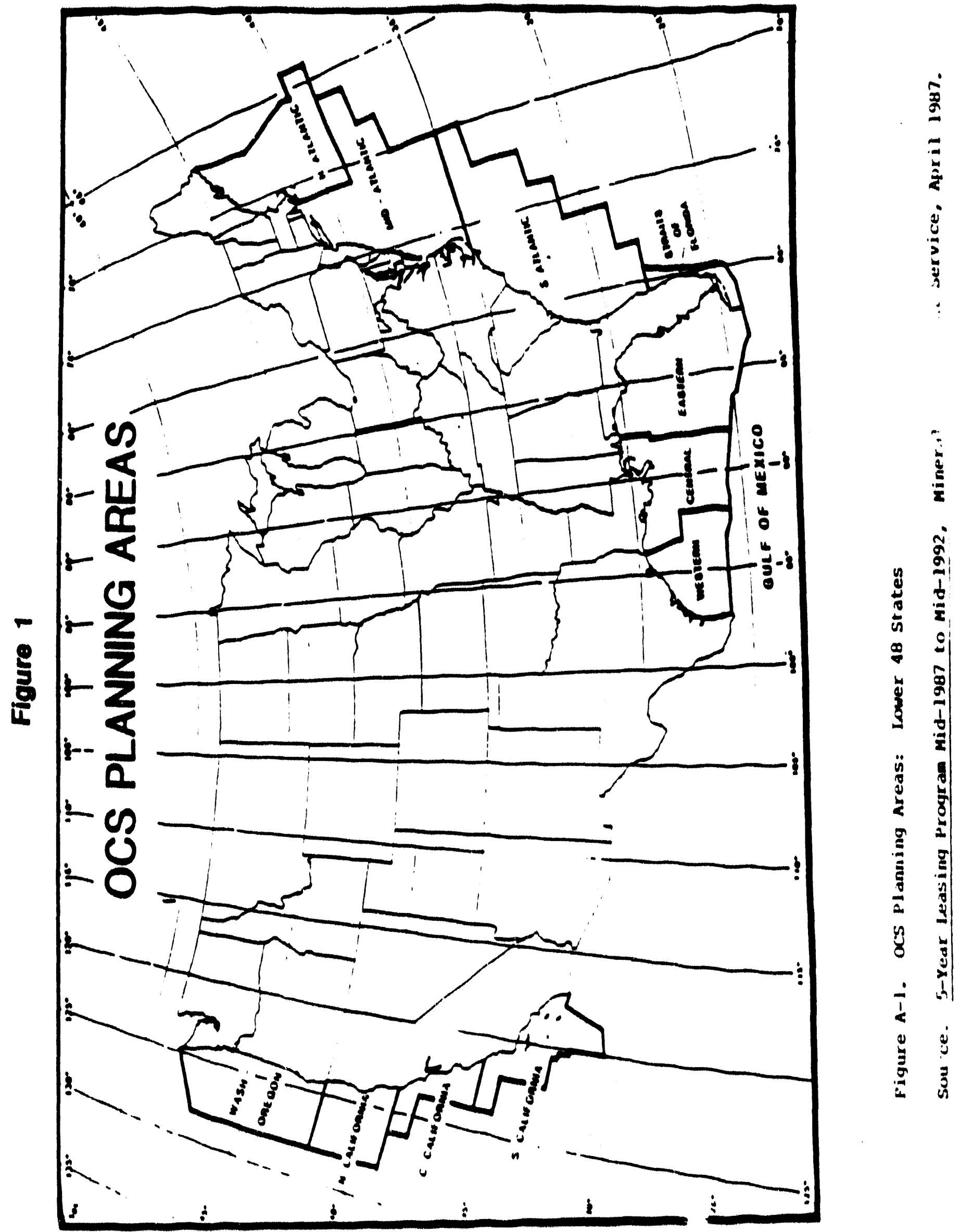




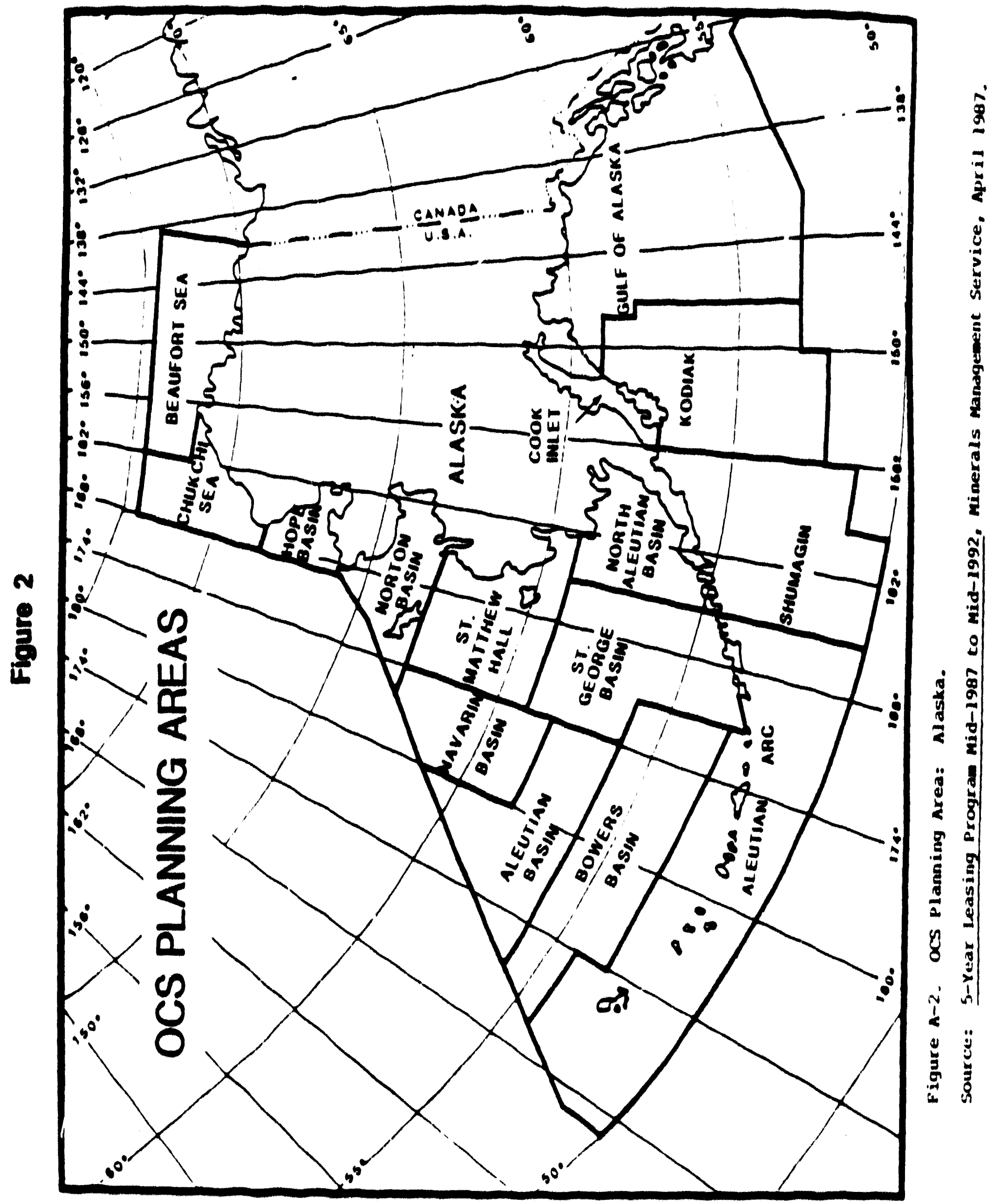


Figure 3

Toxicity and Static Sheen Failure Rates for Water-Based Fluids All Depths

Approaches A \& C

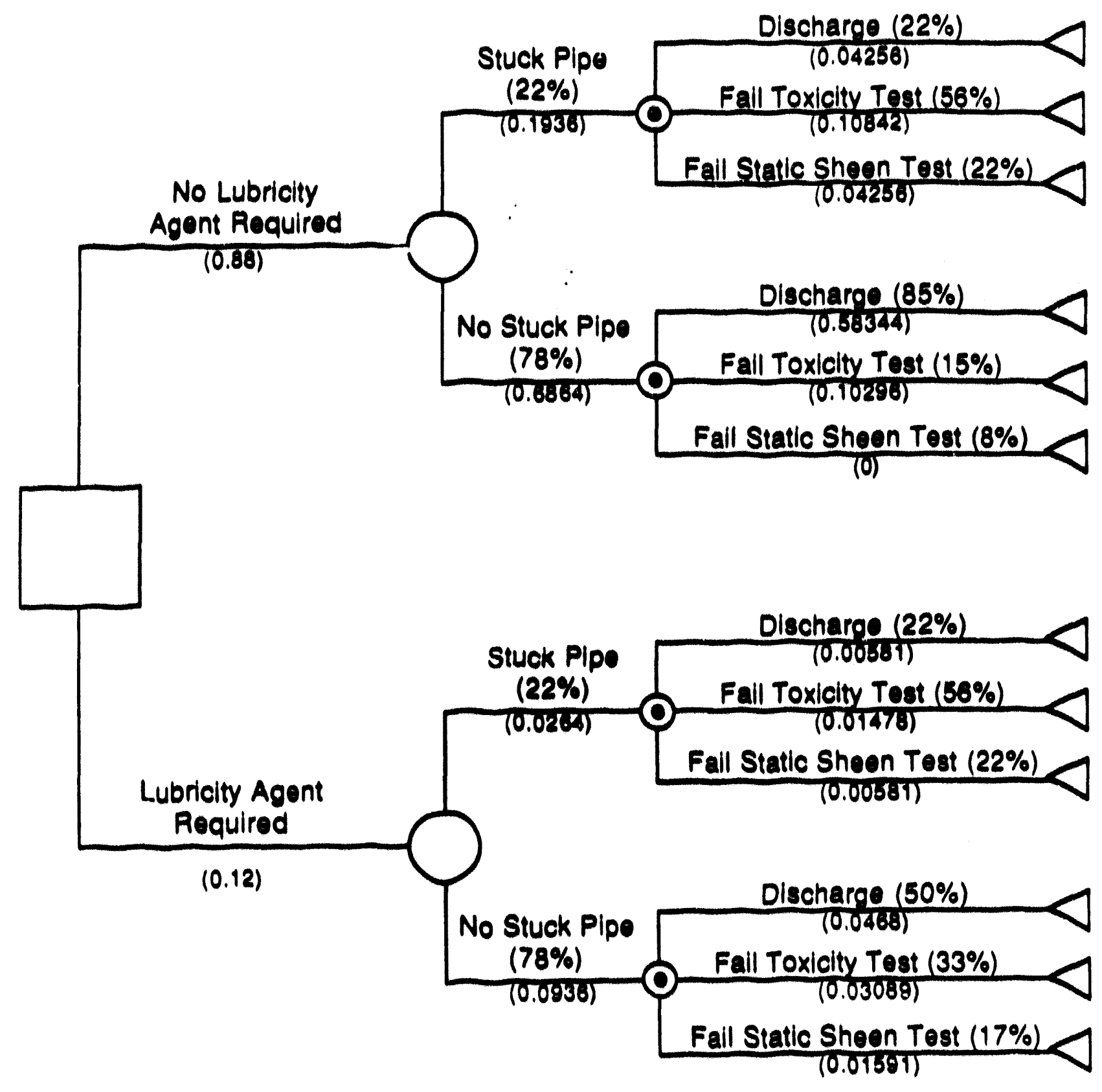

Percent Discharged $=[(0.04256)+(0.58344)+(0.00581)+(0.0468)]+100-68.00$

Percent Faillng Toxicity Test $=\left[(0.10842)+(0.10296)+(0.01478)+(0.03089]^{*} 100-26.00\right.$

Percent Failling Static Sheen Test $=[(0.04256)+(0)+(0.00581)+(0.01591)]]^{* 100}=6.00$ 


\section{Floure 4}

Toxicity and Static Sheen Failure Rates for Water-Based Fluids All Depths

Approaches B \& D

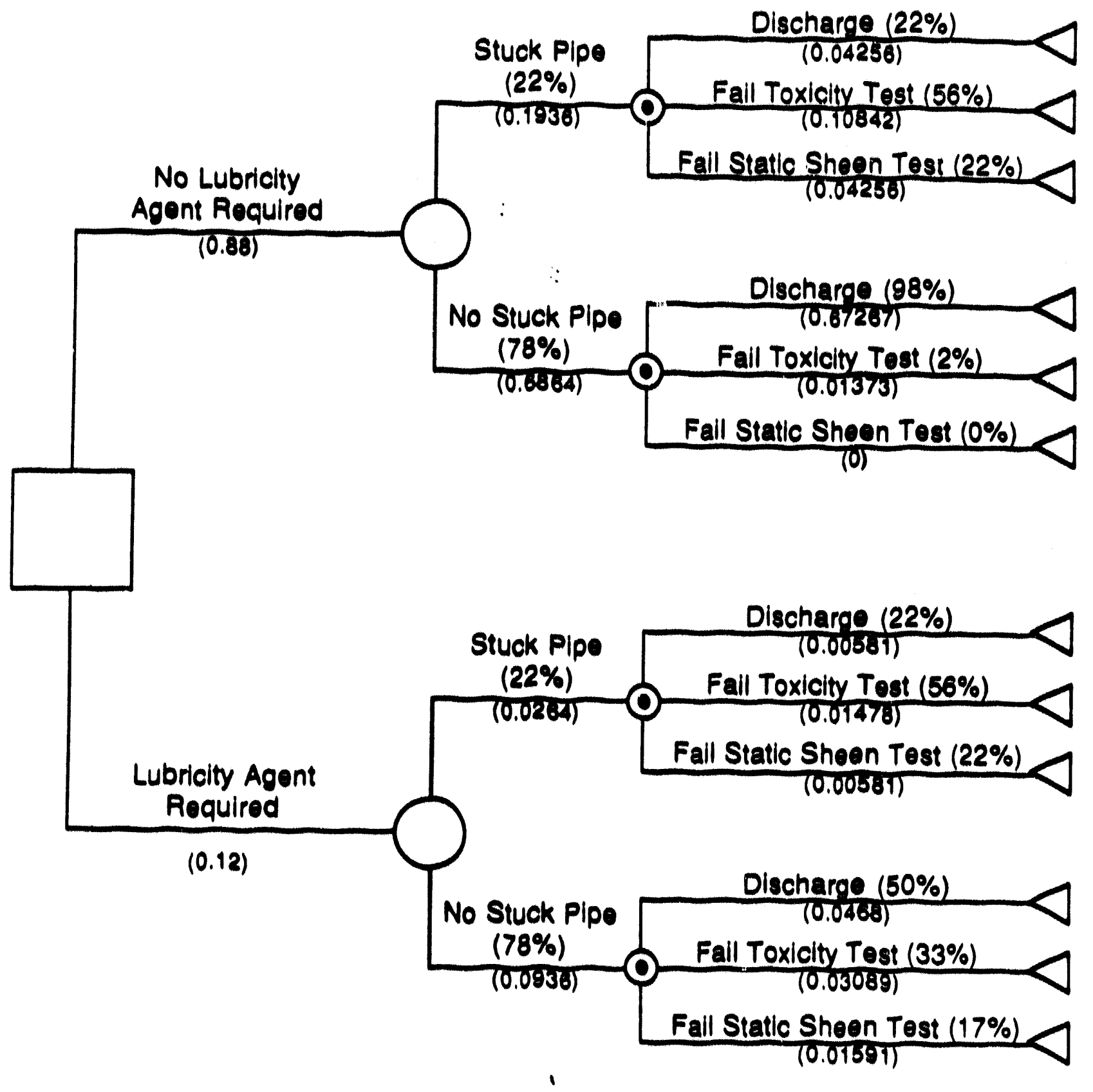

Percent Discharged $=[(0.04256)+(0.67267)+(0.00581)+(0.0468)] * 100=77.00$

Percent Failing Toxicity Test $=[(0.10842)+(0.01373)+(0.01478)+(0.03089] * 100=17.00$

Percent Failing Static Sheen Test $=[(0.04256)+(0)+(0.00581)+(0.01591)]^{*} 100=6.00$ 


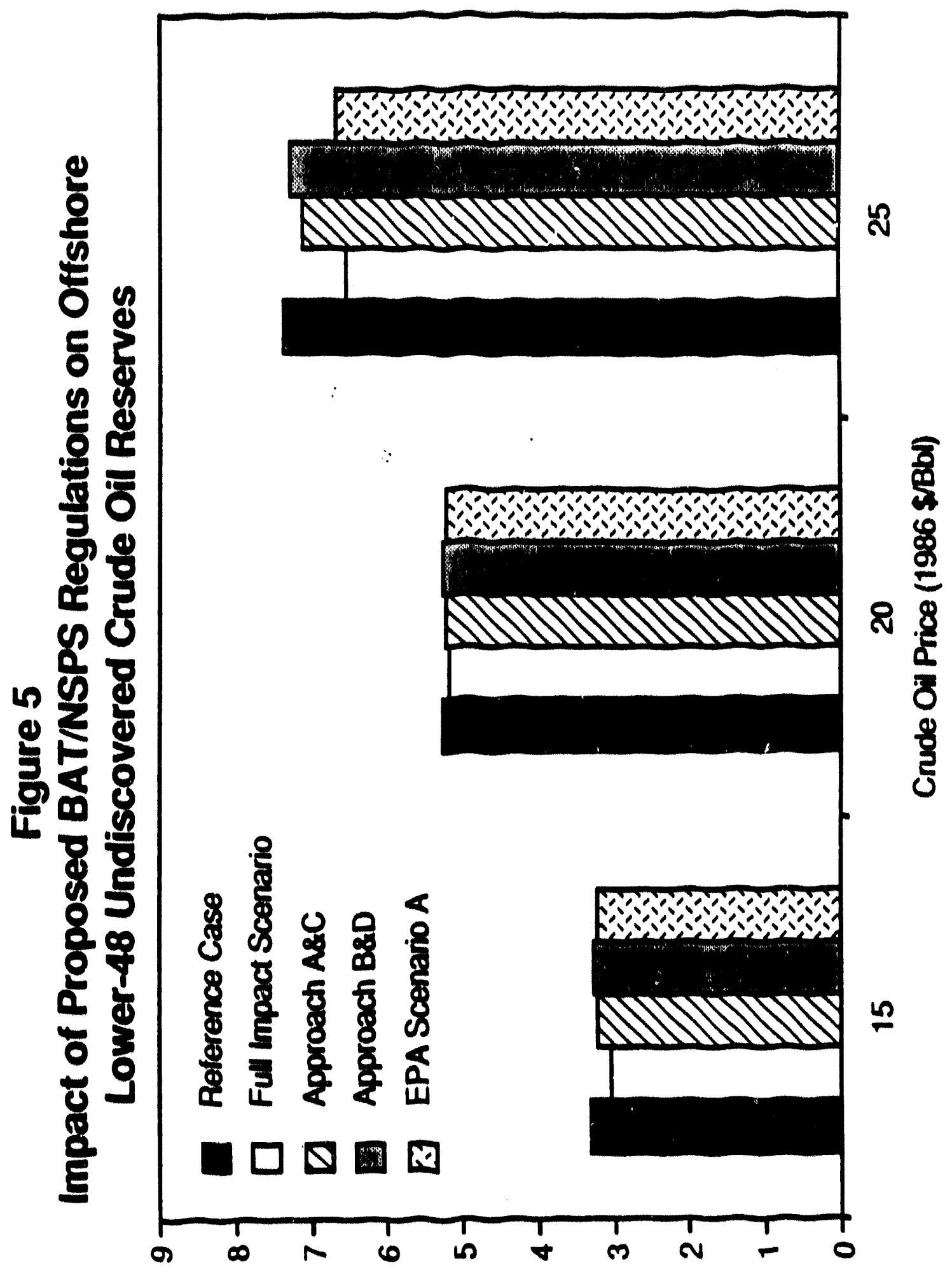

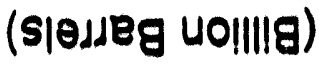

senesey $\| O$ OpNAO 


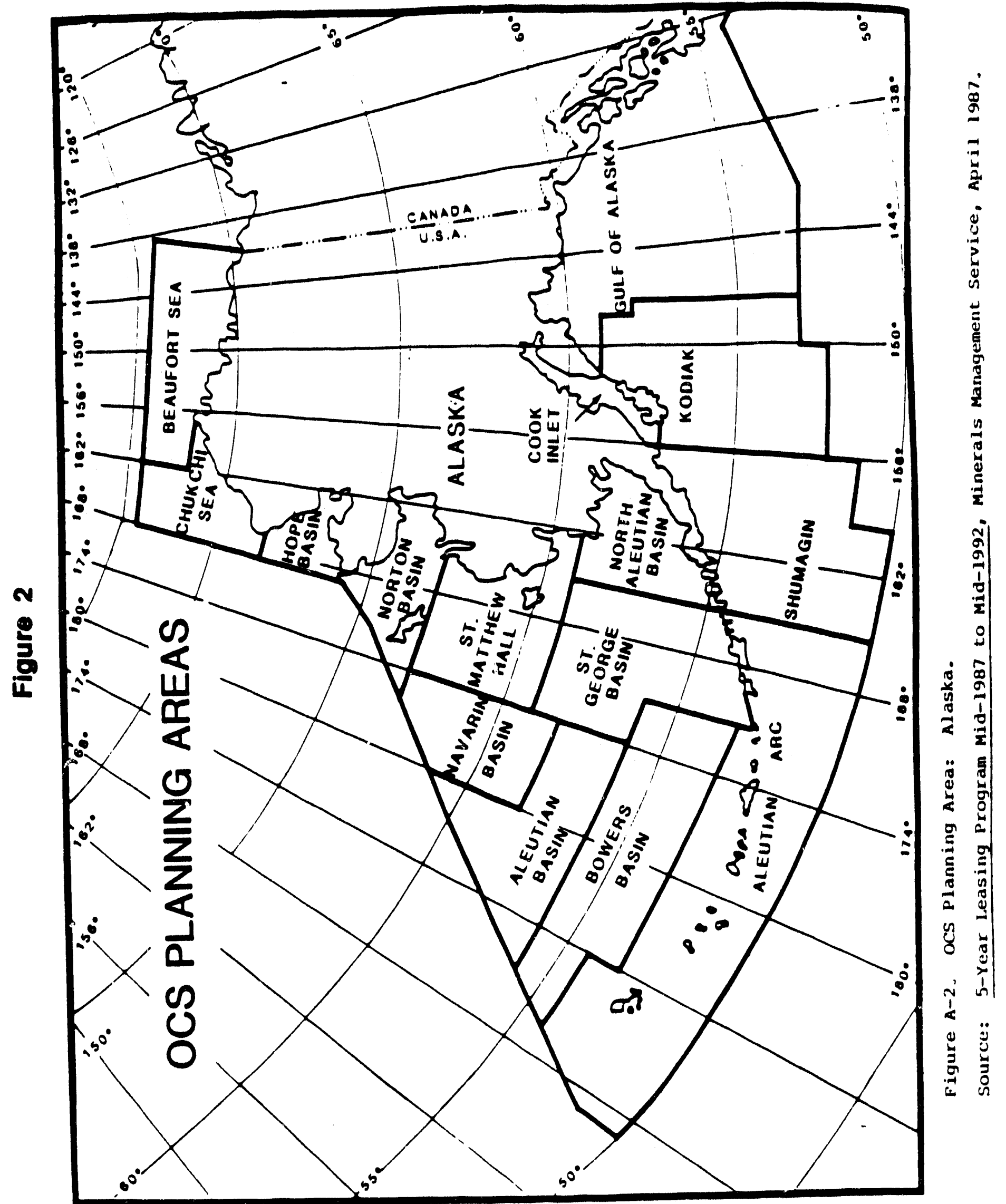


Figure 3

Toxicity and Static Sheen Failure Rates for Water-Based Fluids All Depths Approaches A \& C

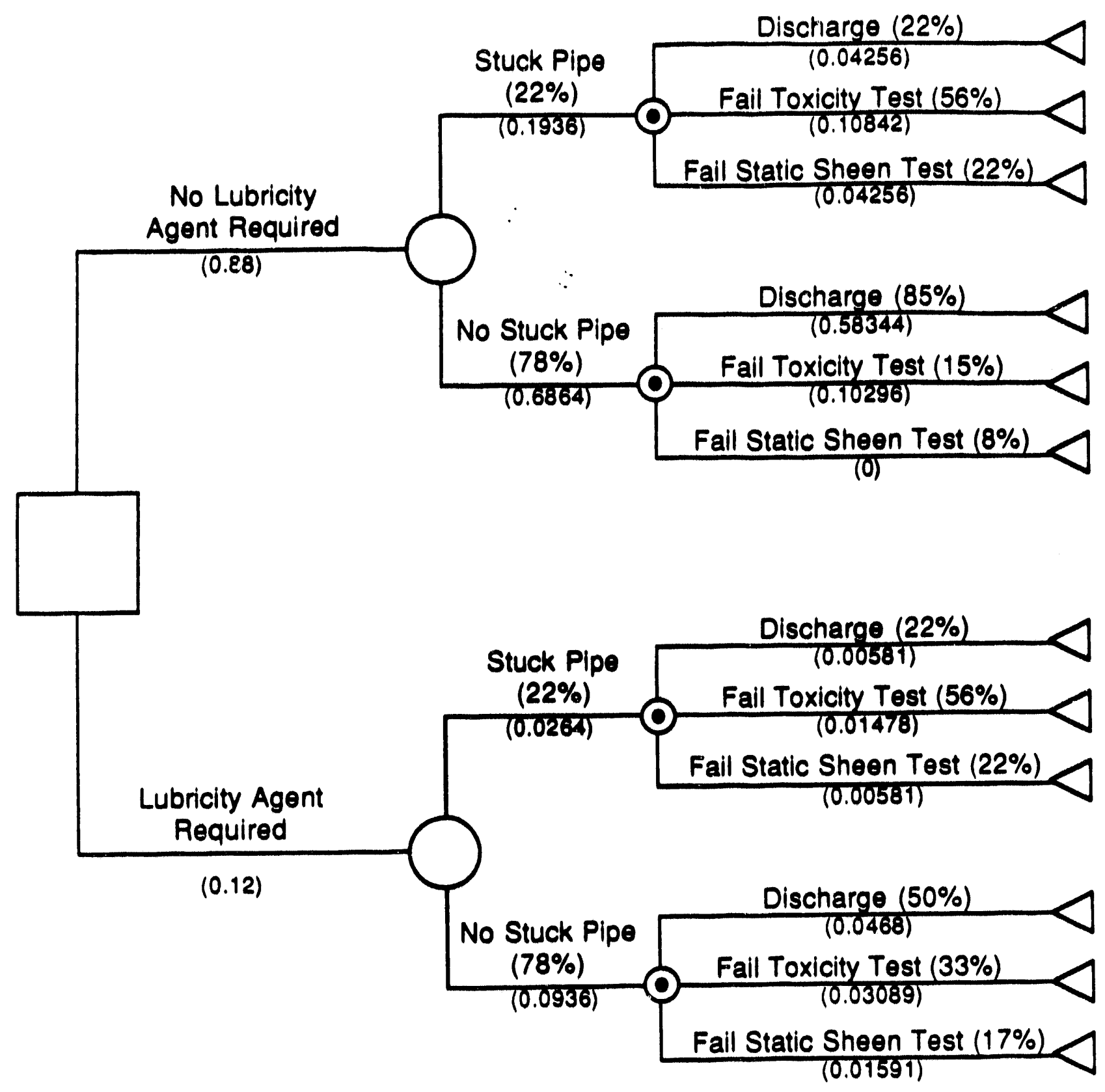

Percent Discharged $=[(0.04256)+(0.58344)+(0.00581)+(0.0468)]^{* 100}=68.00$

Percent Failing Toxicity Test $=\left[(0.10842)+(0.10296)+(0.01478)+(0.03089]^{*} 100=26.00\right.$ Percent Failing Static Sheen Test $=[(0.04256)+(0)+(0.00581)+(0.01591)] * 100=6.00$ 


\section{Figure 4}

Toxicity and Static Sheen Failure Rates for Water-Based Fluids All Depths Approaches B \& D

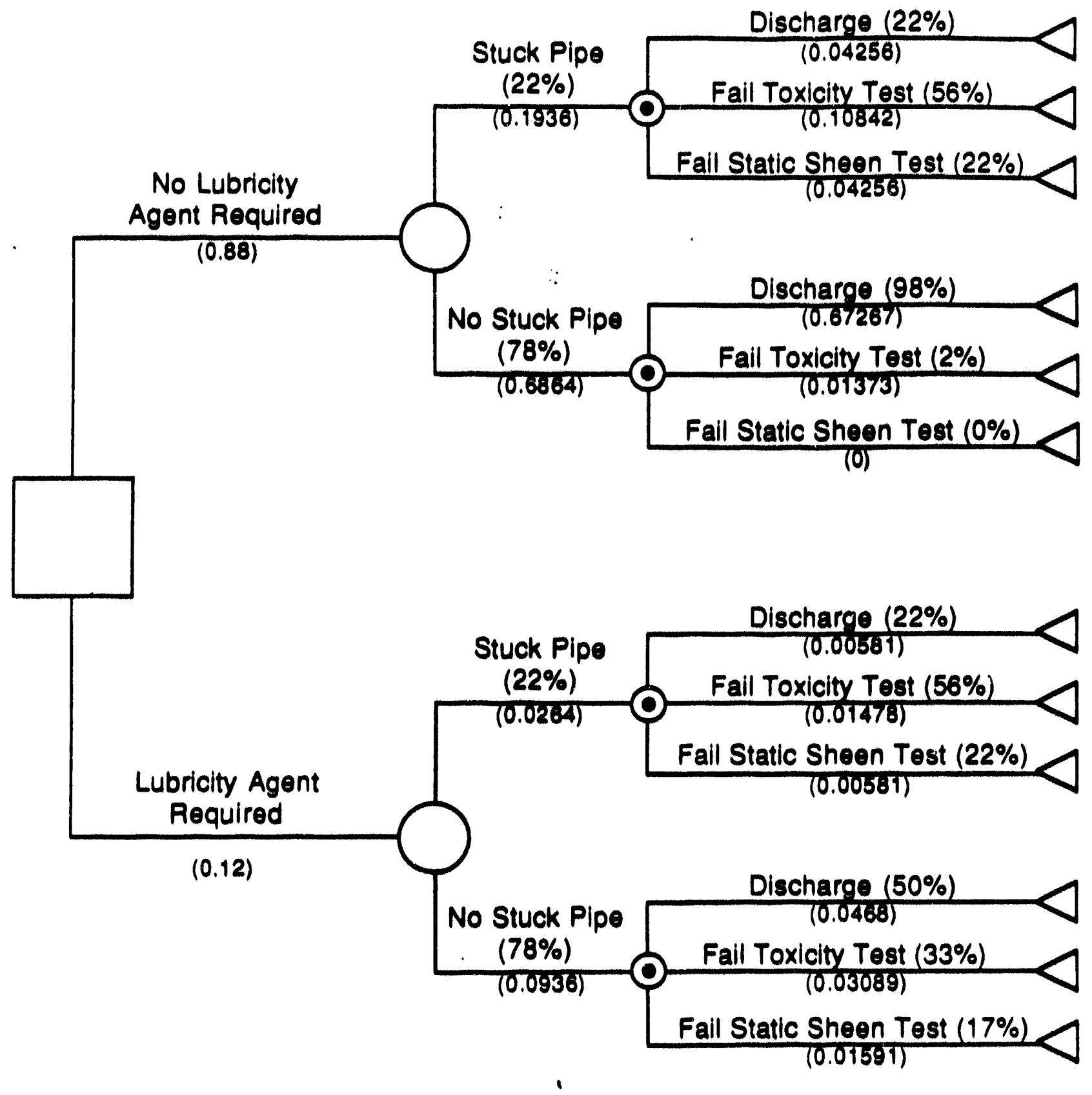

Percent Discharged $=[(0.04256)+(0.67267)+(0.00581)+(0.0468)] " 100=77.00$

Percent Failling Toxicity Test $=\left[(0.10842)+(0.01373)+(0.01478)+(0.03089]^{*} 100=17.00\right.$

Percent Frailing Static Sheen Test $=[(0.04256)+(0)+(0.00581)+(0.01591)]^{* 100}=6.00$ 


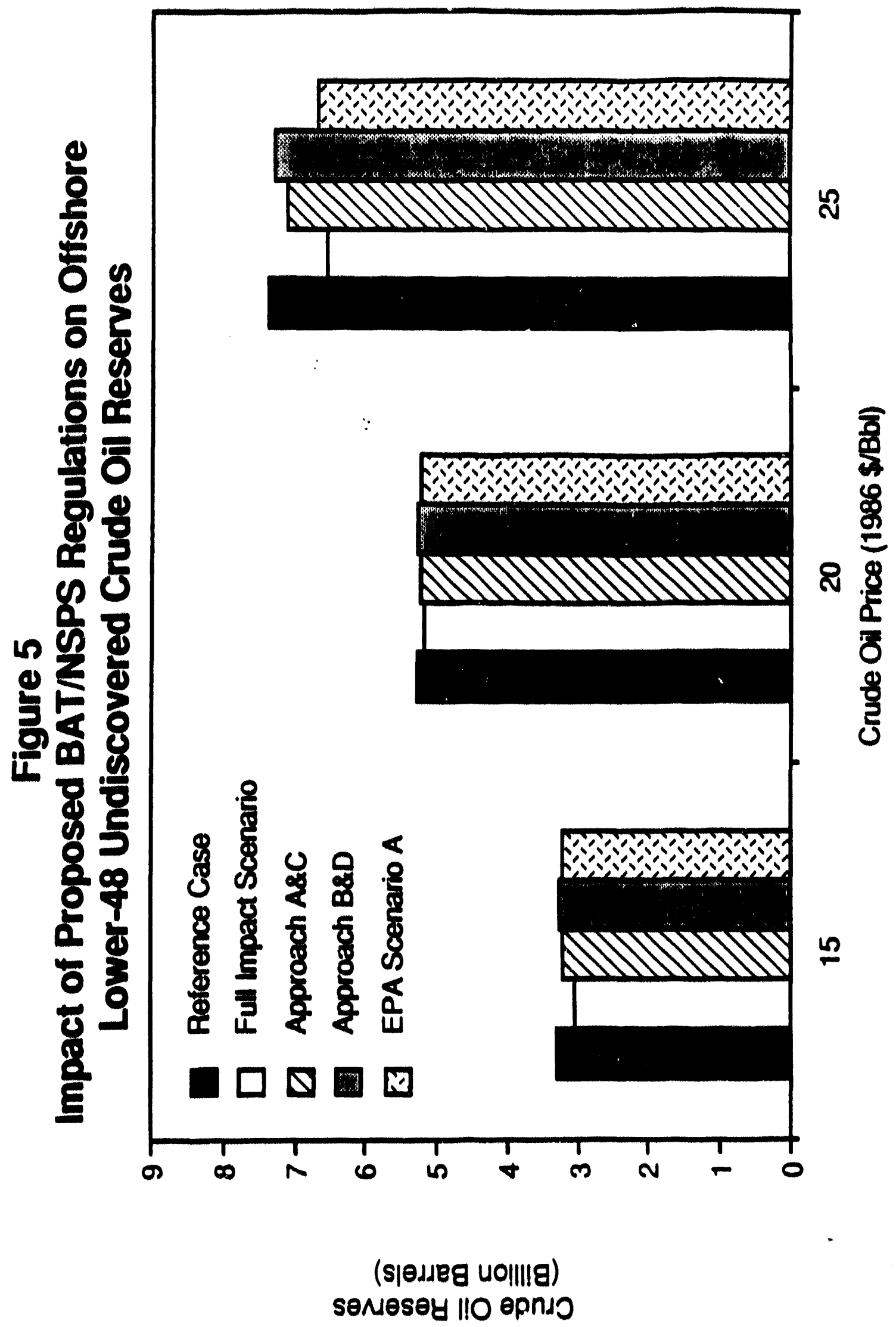




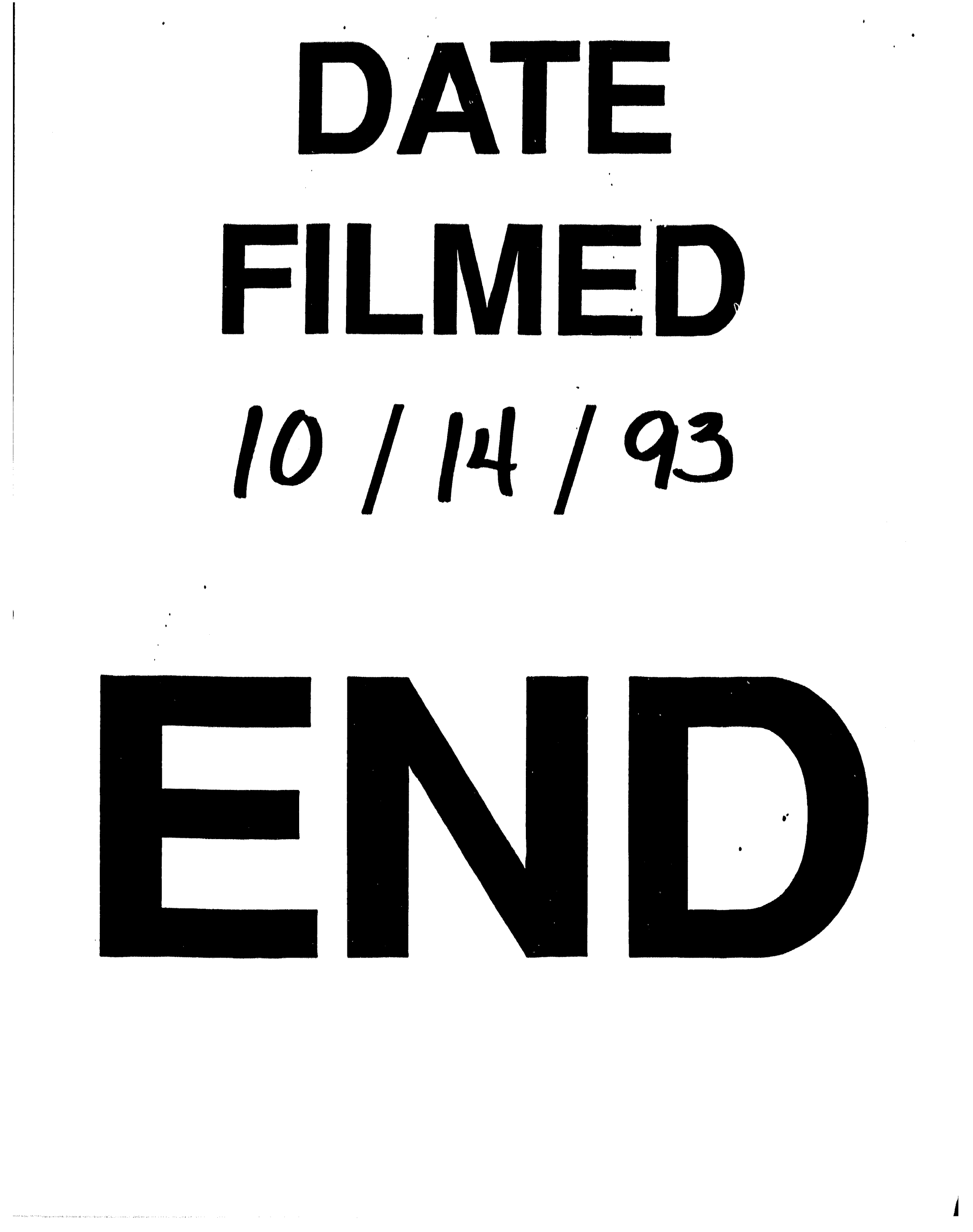


| 